\title{
Facilities Design:
}

\section{What I Learned Along the Way}

by Lynda B. Fowler

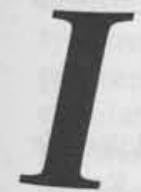

nterviews are designed for the prospective employer to determine if the candidate is the right person for the job and for the prospective employee to analyze the projected job responsibilities. One question I forgot to ask during my interview was about the growth patterns and building plans of the school system. Little did I know that, upon accepting this position as media director, five-and-a-half years later the system would have completed constructing five new schools and renovating one media center; nor, that six new buildings are planned and five media centers will be renovated or replaced during the next five years. The three weeks devoted to facility planning and design during Library Administration 101 over twenty years ago were not adequate preparation for the task. Like most school media coordinators, I had never had an opportunity to put into practice what I did learn in those three weeks. I never even worked in a new facility. My assignments were always in old media centers, the two or three converted classrooms in which establishing a listening/viewing area was a major undertaking since there were only one or two outlets per converted room and each was located in the shelving, most often behind books.

The task before me five years ago was overwhelming - what an understatement! But with the assistance of North Carolina Department of Public Instruction personnel, other media directors and media coordinators, and knowledgeable architects, combined with visits to other facilities and extensive reading, I began this mammoth undertaking.

At times no one would ever have guessed my occupation by looking at my office. Sometimes it resembled a warehouse, at others an architect's office, but most often it appeared to be the result of an encounter with Hurricane Hugo. The past five years have found me surrounded by furniture and fabric samples and proposals for equipment, materials, and sup- plies. Educational specifications, facility reports and updates, and blueprints in various stages have filled chairs, tables, desk, and floor. The planning, writing of educational specifications, designing, constructing, and opening of these new media centers have occurred under two separate administrations, several procedure and planning models, different people in charge of facilities, varying budget constraints, and changing educational programs and emphases. The resulting new media centers are not perfect, yet each is functional and serves the needs of students and teachers.

This experience has not made an expert of me, but it has served to prove the adage that the more one knows the more one recognizes what one does not know. This experience has given me my own set of things to remember as I prepare to enter the second building phase. The literature sufficiently addresses planning, writing educational specifications, dealing with technology issues, and all the bigpicture themes that one preparing to build or renovate a facility needs to know in order to begin. The following is a random sampling of things I have learned and will remember that aren't necessarily covered in everyone else's list.

How to increase the size of the media center in one easy step.

Square footage of the media center more often than not is determined by budget and not by functions and services. When faced with an area that was too small, discussions were held with top administrators. This process gained no additional space. The media coordinator and I then initiated a letter writing campaign to Board of Education members and the superintendent. Square footage for the media center was increased, but the process was received with a somewhat negative response.

A review of preliminary plans for the second new building found the same problem. This time a plea for help went out to the architect. After working with me for an entire afternoon trying to place required furniture and shelving into a much-too-small design, the architect made the all-important call to the administration requesting permission to add additional square footage to the media center. Permission was granted without discussion. Both processes netted the same result; however, the second strategy was indeed a more pleasant experience. I might add that in all subsequent plans the ar- chitects have included six square feet per child or more for the media centers in the preliminary drawings. They have chosen to deal with the space issue before it becomes a problem.

Remember to cover all the bases, or windows in this case. Special efforts were made to provide for natural and artificial light control in all our new facilities. Lights can be operated for each area of the media center from switches in appropriate locations. A small fortune was spent for electric shades to cover clerestories and blinds were purchased for all the windows - well, almost all the windows. No one remembered that the fire escape door was con- 
structed partially of glass. When the lights are dimmed, the shades lowered, and the blinds pulled, there remains the ray of bright light from the fire escape door. The capital outlay budget is gone, and it appears the issue may need to go before the state legislature to obtain funding for one more window covering.

Signs, posters, and student work-but nowhere to hang.

Media Program Recommendations stresses the use of signs for directing students in the media center, the use of posters for creating a pleasing environment, and the display of student work. But anyone who has occupied a new facility knows that the first rule from the principal's office is that nothing - no tape, no hangers, nothinggoes on the new, freshly painted walls. Why didn't someone remind me to include tack strips in the specifications?

Hot School Television programming or how a design idea stopped one step short. Inhouse television distribution centers are unsightly and are often located in inconvenient places. This was one problem that would be solved in our new schools. When presented with the challenge, the architect developed a brilliant solution. A cabinet, designed to match the other casework, was conveniently located in the administrative/planning area. The headend and video equipment were hidden from view and located only a few steps from the main work area. How wonderful-except no one thought about the amount of heat generated from equipment housed in an enclosed area. What was intended as a convenience has ended up causing a major traffic flow problem: the cabinet doors must stay open to prevent the equipment and space from overheating. It may be years before the solid doors can be replaced with ventilated ones.

\section{Circulation area designed to be used in England.}

During the first visit to a new media center after the students arrived, I observed a traffic flow problem around the entrance/exit, circulation area. An obscure statement once read in an article on facility design immediately flashed through my mind. We live in a right-oriented society. One of the first lessons learned in kindergarten is to walk on the right side of the hall. So what was causing the traffic flow problem? The circulation desk was on the left. Students exited the media center directly in the path of students entering the media center. Location of the circulation desk on the right as students leave is now on my list of priority items to check on future initial design plans. No more circulation areas designed for the left-oriented English society for us.

Be prepared when Ma Bell (or whichever daughter or son company) comes calling. A meeting to discuss telephone needs did not appear to merit extensive preparations. Telephone and telecommunication requirements had been identified in the educational specifications and their locations marked on a blueprint. I was prepared for this meeting - or so I thought. No one informed me, however, that an electrical engineering degree was a prerequisite. One's credibility in discussing modems, data lines, and telecommunications diminishes when one has difficulty understanding the terminology. But credibility takes a dive straight to the bottom when one cannot operate the telephone instrument selected for use in a new building. I did manage to recover from the embarrassment and to communicate our needs. Yet I have not formulated a solution to this problem, (and besides, the entire system and individual instruments will probably change before I am faced with another one of these meetings.)

\section{Knowledgeable architects often read wrong.}

A frantic call came from the architect re- questing that I come to his office as soon as possible. I arrived to find him surrounded by the educational specifications, several wasted copies of the blueprint, and a number of empty coffee cups. An expression close to terror and a plea for help greeted me. He could not possibly fit all the shelving designated in the specifications into the media center. After several questions and references to the specifications, we discovered that he was attempting to put the exact number of feet of shelving requested into the space. The word linear had completely escaped him. Much of one's time in the building process involves educating and helping willing architects.

\section{Forever the diplomat.}

I have learned that negotiating skills are essential in the building process. Knowing who to approach, when and how to make your pitch, and being aware of what to fight for and what to be willing to give up are keys to having quality facilities. A large portion of one's time is spent convincing others, especially the person controlling the budget, about how things should be in a school media center. Not only is that person responsible for seeing that each area of a new school receives its fair share, but often this person brings with him personal perceptions of the media program and media center. Perhaps one of my hardest jobs was persuading the $6^{\prime} 4^{\prime \prime}$ administrator (with control of the

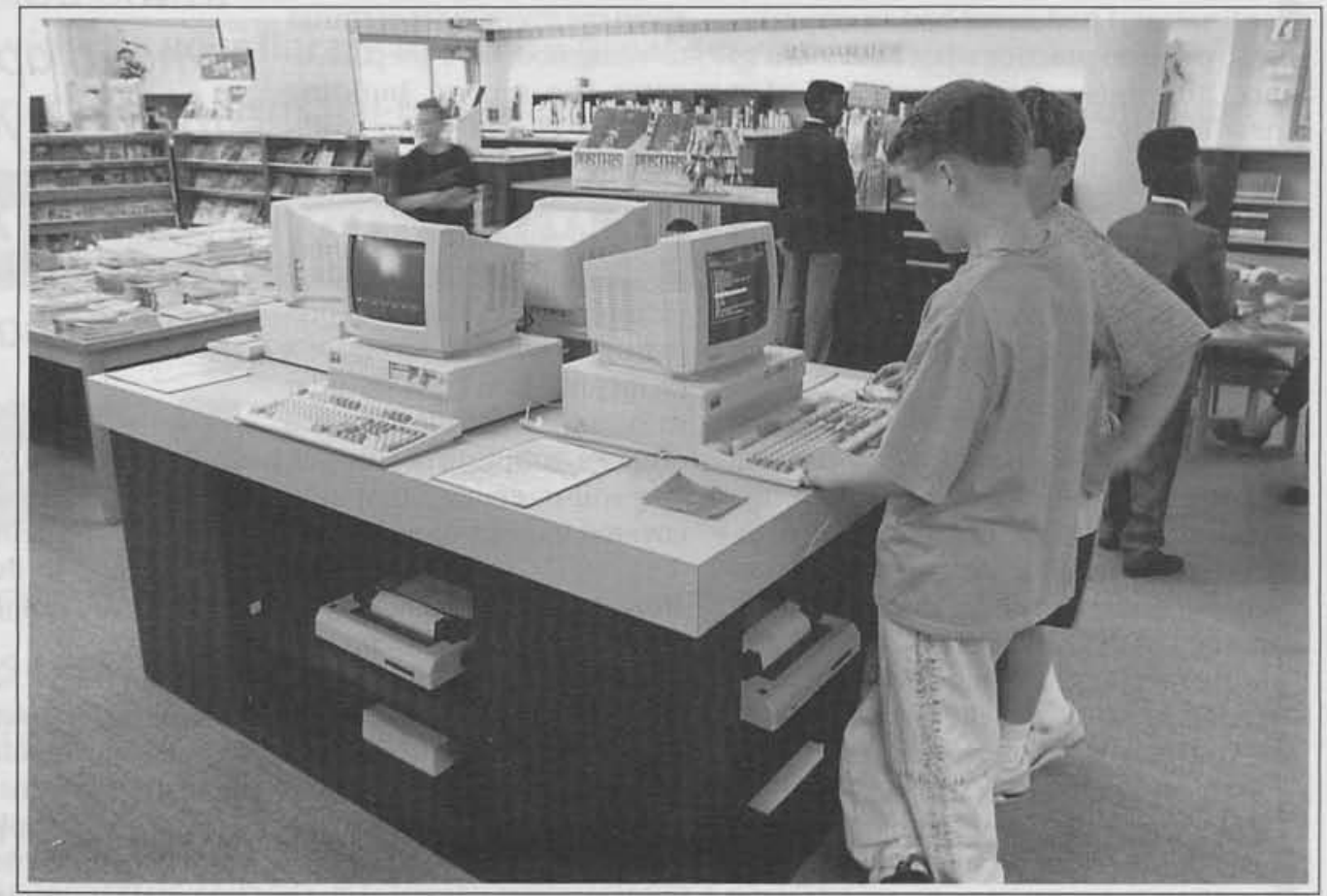

The custom catalog unit in the Bethesda Elementary School (Durham, NC) was designed to accommodate a traditional card catalog,, as well as an automated catalog. The convertible unit was designed by architect John Thompson.

Architect: DePasquale, Thompson, and Wilson (Durham, NC). Photo: Alex Labdon. 
money) that middle school students could not use shelves more than $5^{\prime} 6^{\prime \prime}$ high. He was serious in his proposal to extend the shelving to over six feet and to provide stools for the students. Six feet did not seem too tall for him, and he had used ladders in his university library. Thank goodness my instinct to employ diplomacy overcame my urge to laugh, and the shelving was installed at the appropriate height for middle school students.

Those 800 service numbers are wonderful, but only when a telephone is convenient. Opening a new media facility was exciting; opening it with automated management systems was twice as exciting. The first problem encountered with the automated circulation system that created a need to use the 800 service number brought some of the excitement under control. Having a telephone in the administrative/planning area was wonderful, but no media coordinator could follow directions from that helpful voice on the 800 number when she was not near the circulation desk - another problem no one had foreseen. A telephone at the circulation desk has been added to my list of things not to forget.

\section{White notebooks abound.}

This is a small item, but one that should not go unattended. Examine the amount of shelving needed to house the complete works of the North Carolina Department of Public Instruction better known as The Teacher Handbook. Plan shelving to accommodate the nineteen-volume publication that each school is required to house. Otherwise, space may not be available for the remaining professional collection.

\section{It's the details that often do you in.}

Learn to read the blueprints carefully. The following are examples of what can happen when details are overlooked:

Storage space for poster paper and large construction paper in the production area has exactly the correct dimensions - on the outside of each drawer. The inside dimensions . . . let's just say that poster paper and large construction paper are now stored elsewhere.

The importance of visual supervision was stressed to the architect. A glasspaneled half-wall was installed between the administration/planning and main use areas. All was well until the shelving was put in place. Then I discovered that the shelving covers several inches of the glass panels. No real problem is created, but this is not eye-pleasing.

The computer was measured, needs and functions identified, and the architect and I worked together to design a counter to accommodate automated circulation. Every- thing looked perfect on paper. Why didn't we remember to measure the printer? It now sits at an angle to prevent it from sticking out over the edge of this otherwise very functional, well-designed circulation desk.

All counters, desks, and work spaces in our new buildings are designed by the architects and are built-in casework. This arrangement provides functional, yet compact, work areas. On one plan, I was assured by the architect that the work space arrangement was identical to one in a completed building. Taking his word instead of examining the detailed drawings resulted in no drawer or filing space at the desk area. Invariably, items end up on the floor.

In one school, the interior of the equipment storage space had to be redesigned at the last minute to accommodate access to a mechanical area above the ceiling. The architect asked that I approve the redesign, and all appeared to be fine. 1 did not think to examine the electrical plan. Now a wonderful, much-needed repair counter sits unused because there is no electrical outlet near it. These problems are not monumental and do not seriously interfere with the operation of the media centers, but each could have been prevented had I paid closer attention. Those minute details will get you every time.

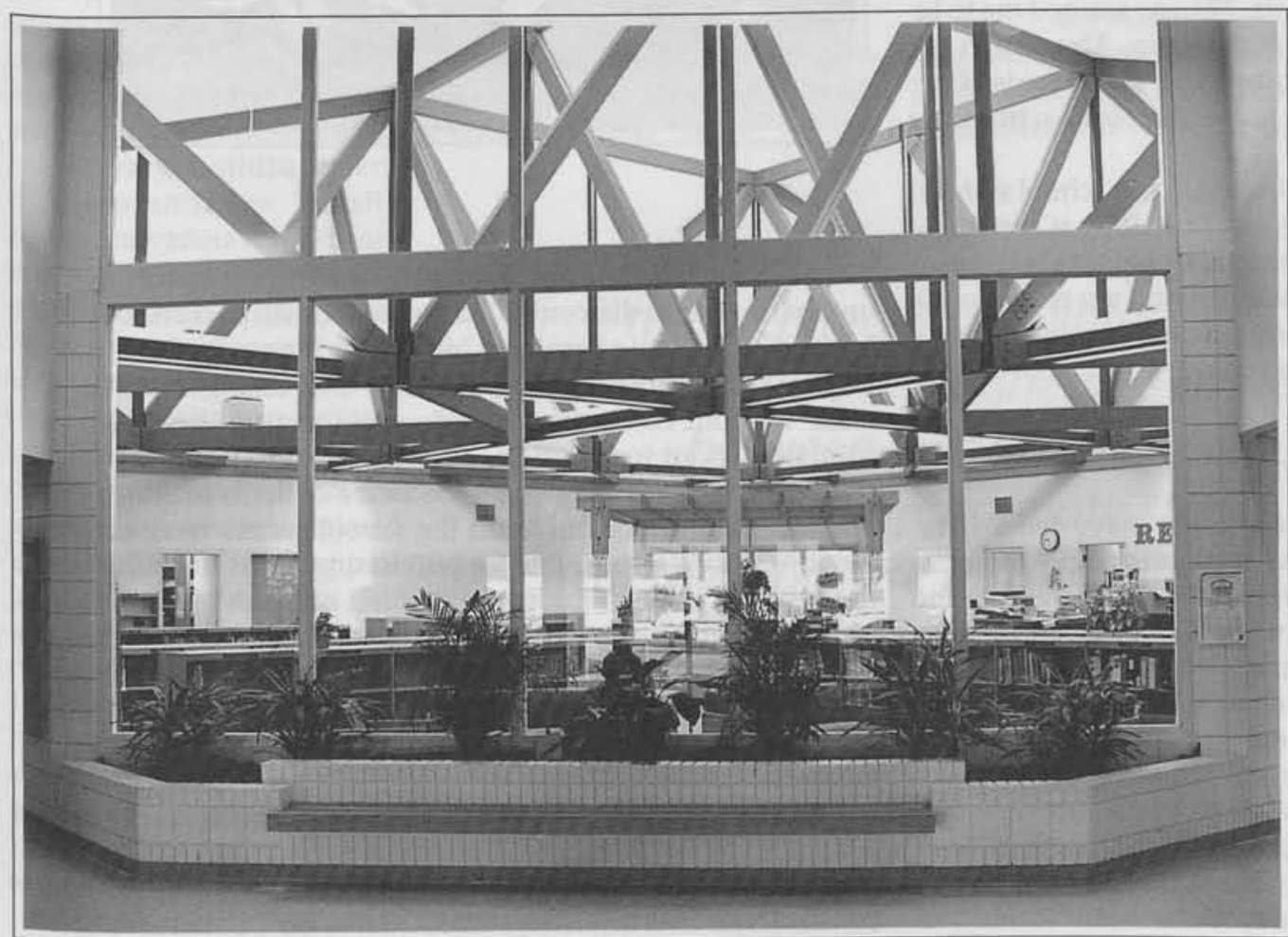

The media center at Vance Elementary School, in Raleigh, features striking double height vaulted beams designed by architect Larry Deckard. Viewed through a glass wall in the lobby is a uniquely combined circulation desk/information files/display shelving/catalog unit in a U-shape.
Boy, was my face red.

At one point the architects called with a design problem for a particular storage unit. I was to think about the problem and meet with them the following day. As I thought, I began to sketch a plan. The next day I appeared at their office with my drawing in hand. I quickly realized that the rule about letting the architect design holds true even for small items. I began to laugh with them, excused my feeble attempts, and gave them the information they needed. I will never forget that a well-designed media center is the result of a knowledgeable architect interpreting information from a knowledgeable media person.

Preparedness-what agrandidea. Being prepared not only involves reading and studying about facilities and learning how to write quality educational specifications, but it also includes being mentally and physically prepared to deal with all subsequent building stages. Often the most trying phase of the building process is the lastthe punch list-when the build- 


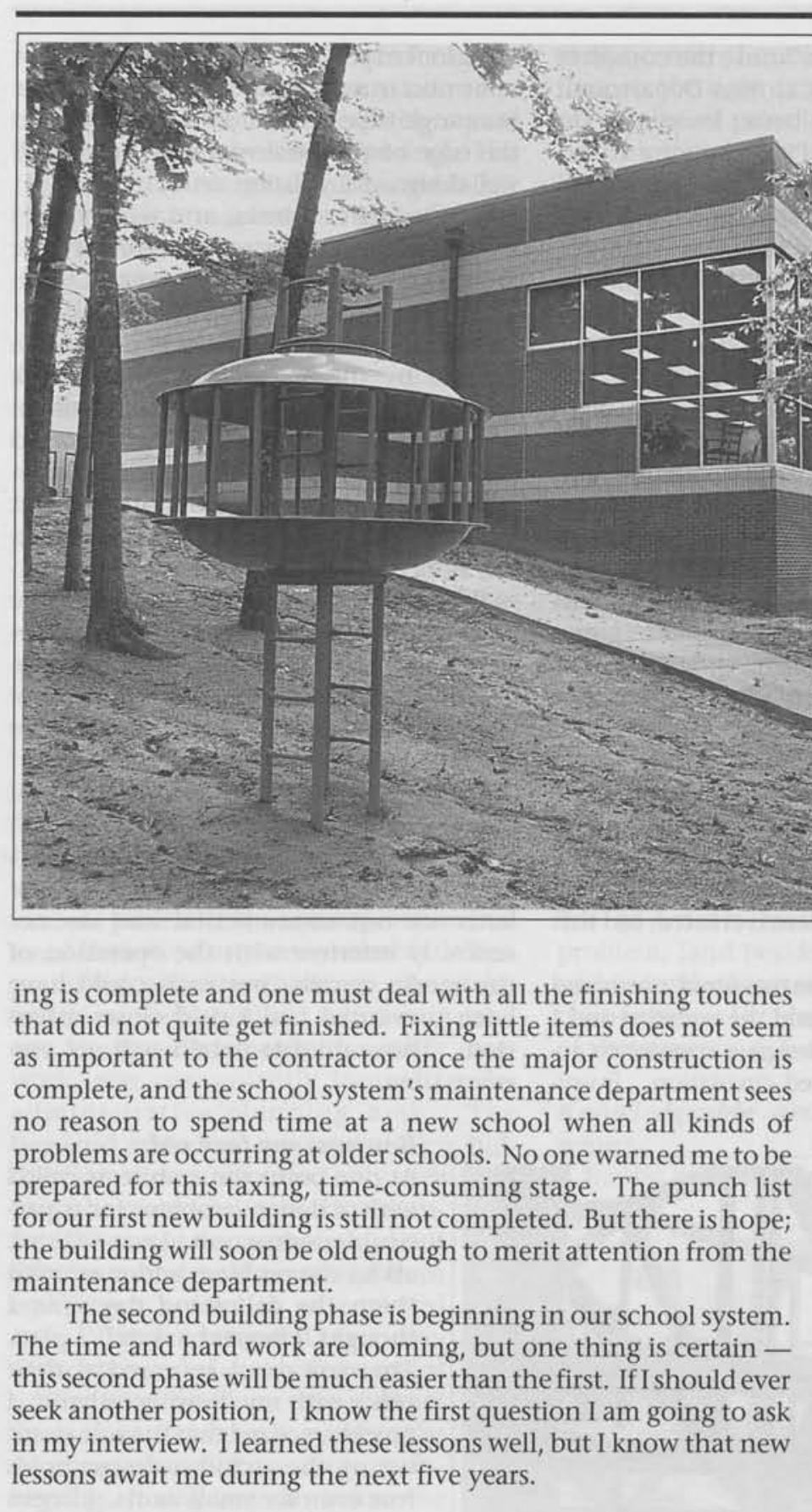

\section{Ten Helpful Pointers}

Experiences during the first building phase have led to the development of a personal set of rules to follow in future projects. Hopefully, adherence to these rules will enable me to weather the planning, design, and construction storm successfully.

1. Research and study the literature. Do not limit this to facility design, but include topics such as space and aesthetics and their effects on behavior, learning, and productivity; trends in media, technology, instruction, and education in general; color; and ergonomics.

2. Write concise, thorough educational specifications. Depend on the specifications as the guide through each step of the building process.

3 . Let the architect design, but supply the necessary program information to ensure a quality plan.

4. Identify the roles of all persons involved in the building process and establish a working relationship with each.

Understand the protocol.
Design maximizes the view to the adjacent woods in the remodeled Allenbrook Elementary School in Charlotte. The large glazed corner at the storytelling area makes this a "special place" in the main reading room.

Architect: Greg Long

(Charlotte, NC). Photos: Phil Knowlin.

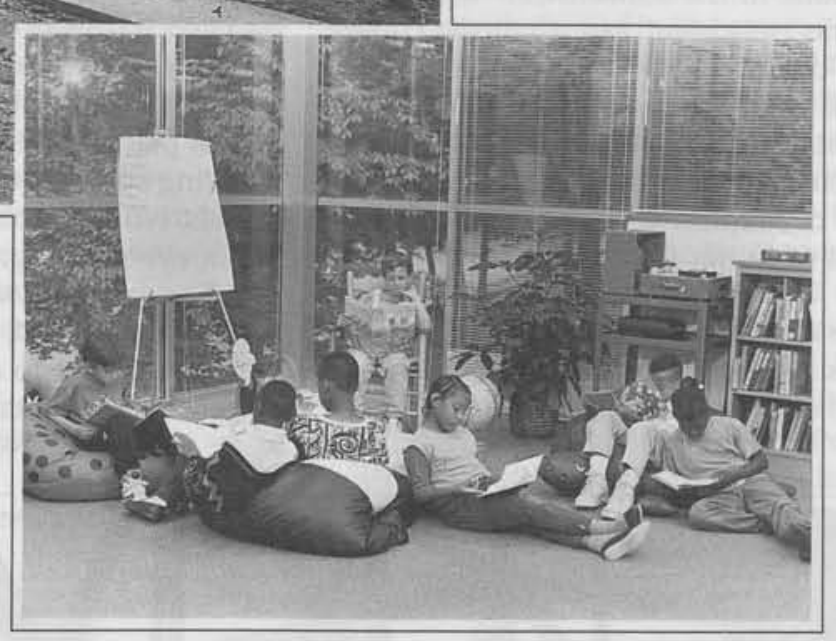

5. Know the building project timeline. Add to this items involving the media center. Items to add will include obtaining and submitting furniture bids; ordering equipment and materials; determining the point at which changes can be made without costly change orders; contacting the cable company about installation.

6. Understand the budget. Be aware of items included in the general contract and items the school system must furnish. Identify who is responsible for purchasing items not supplied in the general contract. Know the amount of funds available for furniture, window coverings, equipment, materials, automation, networking, and other items necessary for the media center.

7. Examine all blueprints and drawings carefully. Don't overlook the electrical and networking plans or the detailed drawings for casework.

8. Complete a walk through of all media center services and activities on the blueprints. Determine if electrical outlets, light controls, networking outlets, and telephone lines are located for convenience and efficiency. Check traffic flow patterns. Determine if the design and placement of furniture and shelving allow for visual supervision by the media center staff.

9. Be diplomatic. Be willing and prepared to negotiate.

10. Plan to spend a considerable amount of time with the building process. Allocate enough time to complete tasks. 